\title{
Influence of ground motion duration on ductility demands of reinforced concrete structures
}

\author{
Eric De Jesus Vega ${ }^{1} \cdot$ Luis A. Montejo ${ }^{2}$ (i)
}

Received: 14 May 2019 / Accepted: 17 October 2019 / Published online: 25 October 2019

(c) The Author(s) 2019

\begin{abstract}
This article investigates the level of influence that strong motion duration may have on the inelastic demand of reinforced concrete structures. Sets of short-duration spectrally equivalent records are generated using as target the response spectrum of an actual long-duration record. The sets of short-duration records are applied to carefully calibrated numerical models of the structures along with the target long-duration records. The input motions are applied in an incremental dynamic analysis fashion, so that the duration effect at different levels of inelastic demand can be investigated. It was found that long-duration records tend to impose larger inelastic demands. However, such influence is difficult to quantify, as it was found to depend on the dynamic properties of the structure, the strength, and stiffness degrading characteristics, the approach used to generate the numerical model and the seismic scenario (target spectrum). While for some scenarios, the dominance of the long record was evident; in other scenarios, the set of short records clearly imposed larger demands than the long record. The detrimental effect of large strong motion durations was mainly observed in relatively rigid structures and poorly detailed flexible structures. The modeling approach was found to play an important role in the perceived effect of duration, with the lumped plasticity multilinear hysteretic models suggesting that the demands from the long records can be up to twice the inferred from distributed plasticity fiber models.
\end{abstract}

Keywords Ground motion duration · Incremental dynamic analysis $\cdot$ Reinforce concrete structures $\cdot$ Nonlinear modeling

\section{Introduction}

In structural design and assessment, the preferred representation of seismic hazard continues to be based on the elastic response spectrum. Even when dynamic timehistory analyses are required, the acceleration time histories used are usually required to be compatible with a prescribed design spectrum. One option to comply with this requirement is to use spectrally matched records. The criteria for developing these time histories is provided in design codes and guides like the 2015 NEHRP Recommended Seismic Provisions (BSSC 2015) and the Appendix F of the US Nuclear Regulatory Commission

Luis A. Montejo

luis.montejo@upr.edu

1 Department of Civil Engineering and Surveying, University of Puerto Rico at Mayaguez, Mayagüez, PR, USA

2 Department of Engineering Science and Materials, University of Puerto Rico at Mayaguez, Mayagüez, PR 00680, USA
RG-1.208 (US-NRC 2007). While most of the criteria in these documents are devoted to quantifying the required level of matching, limitations on strong motion duration are no explicitly established (e.g., NEHRP, for conventional structures) or are rather vague (e.g., RG-1.208, for nuclear facilities). Prescriptions regarding duration on the US-NRC RG-1.208, for example, are limited to check that the spectrum-compatible series have durations consistent with characteristic values for the magnitude and distance of the events controlling the design spectrum. This absence of duration regulations is likely due to earlier research works on this topic finding correlation between duration and cumulative damage metrics but no with peak deformations, which are the base of the seismic acceptance criteria (Chandramohan 2016). For a comprehensive review of earlier works, see Hancock and Bommer (2006). Nevertheless, more recent studies that made use of more realistic structural models (i.e., models that account for cyclic strength/stiffness degradation and p-delta effects) have found positive correlations between duration of the strong motion excitation and peak deformations. 
Montejo and Kowalsky (2008) found that duration influences mainly the peak inelastic demand of short-period structures with stiffness and strength degradation and subjected to relatively large level of inelastic demand. Chandramohan (2016) examined the collapse capacity of a modern steel moment frame and a reinforced concrete bridge pier using sets of spectrally equivalent short- and long-duration records. When using the long-duration set, the median collapse capacities were found to be $29 \%$ and $17 \%$ lower for the frame and pier, respectively. Barbosa et al. (2017) investigated the effect of duration on steel moment resisting frames of 3, 9, and 20 stories. They observed that the effect of duration on peak deformation becomes palpable for scenarios, where the lateral demand surpasses interstory drift ratios of $\sim 4 \%$. Molazadeh and Saffari (2018) investigated the effect of duration on single degree of freedom systems with different hysteretic behaviors and periods of vibration, and they found that duration has a substantial effect in short-period pinchingdegrading models. Bravo-Haro and Elghazouli (2018) performed nonlinear analyses on 50 numerical models of steel moment frames using a suite of 77 spectrally equivalent pairs of short and long records as input. As the previous studies, they noticed that the effect of duration is larger for structures that exhibit cyclic degradation and becomes more pronounced at increasing levels of lateral demand. A typical reduction of about $20 \%$ in the collapse capacity was observed, with up to $40 \%$ for buildings with significant cyclic deterioration.

This article investigates the level of influence that strong motion duration may have on the inelastic demand of reinforced concrete (RC) structures. Moreover, given the scarcity of long-duration strong motion records, the numerical simulation campaign is aimed to answer the question: would the seismic inelastic behavior of a reinforced concrete structure exposed to a very long-duration record (i.e., SD5-75 $>20$ s) be properly captured by a set of spectrally matched records of short duration (i.e., SD5-75 $<20$ s) sharing the same response spectra than the long record? Specific objectives/tasks include:

1. Evaluate the influence of strong motion duration on the seismic response of structures with different dynamic properties and degradation parameters For this purpose, numerical models are developed for an RC bridge column and for an RC squat wall. Both models are calibrated using large-scale experimental data, and then, the parameters affecting the cyclic deterioration characteristics are altered to obtain a second pair of models' representatives of poor detailed structures.

2. Identify the influence of duration at different levels of inelastic demand To accomplish this, the seismic input is applied to the numerical models in an Incremental
Dynamic Analysis (IDA, Vamvatsikos and Cornell 2002), where a set of ground motions is scaled to different intensity levels, so that predefined structural performance levels can be studied.

3. Asses if the modeling approach employed to simulate the response of the structure impacts the observed duration influence Two modeling approaches are engaged to assess the impact of the modeling strategy on the observed duration influence. One approach is based on distributed plasticity using unidirectional fibers and the other lumps the inelastic action to the hinge, which is modeled using Modified Ibarra-Medina-Krawinkler Deterioration Models (Ibarra et al. 2005; Lignos and Krawinkler 2012).

\section{Development of the structural models}

The structures analyzed are maintained simple in geometry, that is, their dynamic response is mainly dominated by their fundamental mode. This allow us to focus on the deterioration characteristics (i.e., cyclic strength and stiffness deterioration) and p-delta effects at large inelastic demands that have been identified as the mechanisms by which duration may influence structural response (Chandramohan et al. 2017). Two different types of structures are analyzed: a single column bridge bent and a squat reinforced concrete wall. These two types of structures were selected to have two fundamentally different scenarios in terms of the dynamic behavior and lateral deformation mechanisms. While the bridge column represents a long period and ductile structure dominated by flexural deformations, the squat wall is rather rigid and dominated by shear deformations. Nevertheless, a drawback is that both cases exhibit a low degree of redundancy which also affect the structure ductility capacity. All the structural models in this research were developed within the OpenSees software framework system (McKenna et al. 2000).

\section{RC bridge column models (ductile, original column)}

For the column, two modeling approaches are engaged, one based on distributed plasticity using unidirectional fibers and the other lumping the inelastic action at the hinge. Having the same structure modeled using two significantly different methodologies allows us to identify if the duration effect is influenced by the approach used to model the structure. Both models were calibrated using experimental data from a series of large-scale shake table tests. Once calibrated, the degradation parameters in the models are varied to analyze the effect of duration on different deterioration scenarios. 
The experimental tests used for calibration were performed in 2010 at the Network for Earthquake Engineering Simulation (NEES) large high-performance outdoor shake table at the University of California, San Diego-UCSD. The column had a height of $7.32 \mathrm{~m}$ and a circular cross section of $1.22 \mathrm{~m}$ in diameter. A total of 18 No. 11 bars provided the longitudinal reinforcement and butt-welded double no. 5 hoops spaced $15.2 \mathrm{~cm}$ provided the transverse reinforcement to the column. At the top of the column, a superstructure consisting of reinforced concrete blocks contributed an estimated weight of $2320 \mathrm{kN}$ ( 237 ton-force). Figure 1 shows a scheme of the setup and pictures of the actual specimen. The tests consisted of a sequential load of ten ground motions (EQ1-EQ10) with different intensity levels, from low to high intensity, bringing the column to near-collapse conditions. The wide range of seismic performances the column experienced, combined with the column height and large mass on the top, make of these series of tests an ideal data set to validate modeling approaches aimed to account for cyclic degradation and large inelastic deformations. Further details on the experimental test are available in Schoettler et al. (2015).

\section{Fiber-based model}

A distributed plasticity fiber-based approach is first engaged to construct the numerical models for the UCSD column. In this approach, the column section is modeled using unidirectional fibers with constitutive relationships for each of material: reinforcing steel, cover concrete (unconfined), and core concrete (confined), as shown in Fig. 2 (left). The reinforcing steel bars were modeled using the OpenSees ReinforcingSteel material (Mohle and Kunnath 2006) that takes into account degradation of strength and stiffness due to cyclic loads according to a Coffin and Manson fatigue model. To avoid localization issues, the number of integration points and element lengths was chosen, such that the integration weight of the fixed node matched the expected plastic hinge length. Second-order effects were included using the OpenSees P-Delta coordinate transformation command and
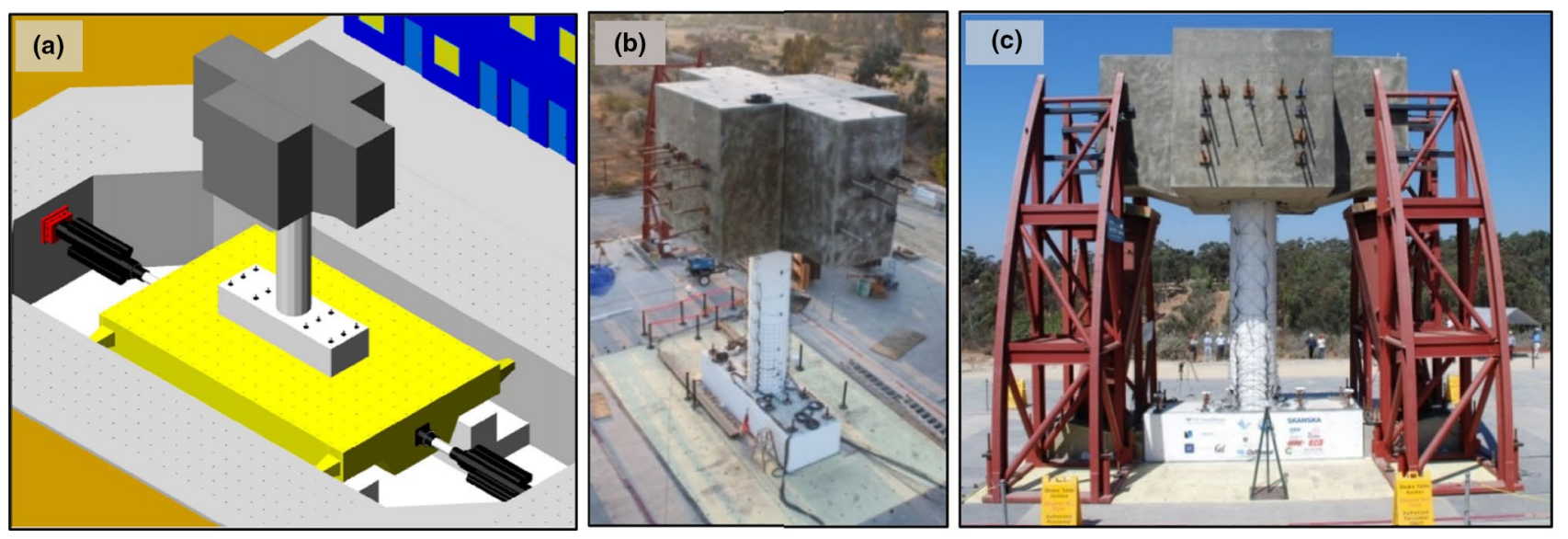

Fig. 1 Full-scale bridge column test: a 3D view scheme setup, b 3D view from top, c front view. Photos taken from: https://nees.org/warehouse/ project/987/
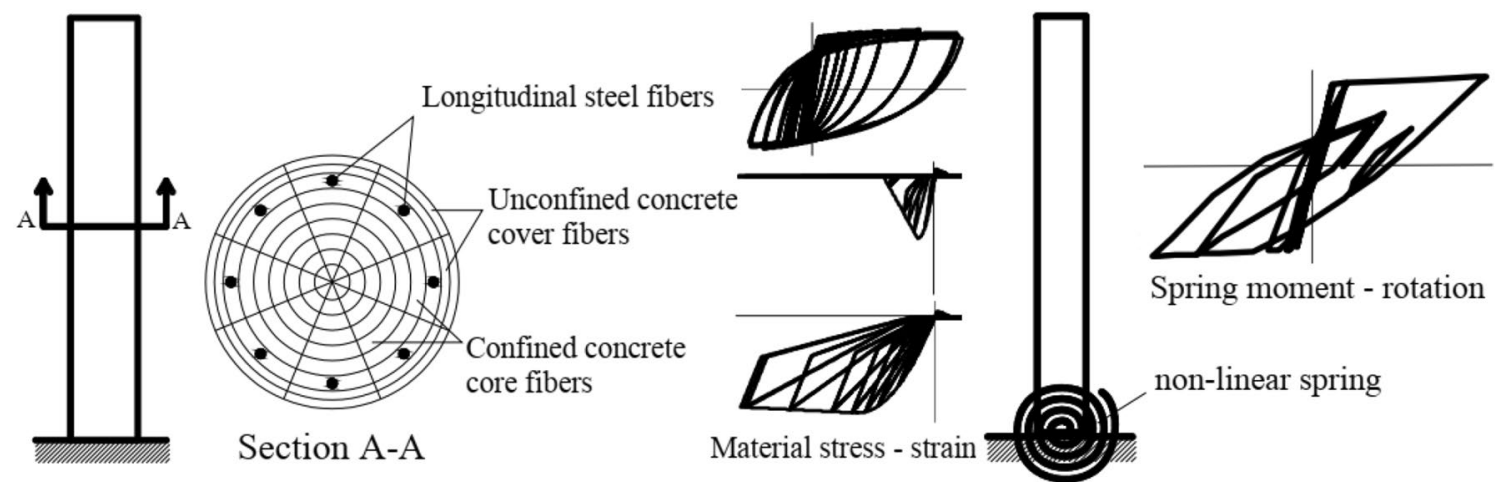

Spring moment - rotation

non-linear spring

Fig. 2 Fiber-based distributed plasticity (left) and lumped plasticity (right) models for a RC column 
elastic damping is included as $2 \%$ tangent-stiffness-proportional damping. Further details on the numerical model are available in Aguirre et al. (2013).

\section{Lumped plasticity model}

In the lumped plasticity modeling approach, the column is modeled using a linear elastic element connected to a zero-length element at the base that represents a rotational spring, where the inelastic deformations are concentrated (Fig. 2-right). The "ModIMKPeakOriented" material available in OpenSees is used to define the behavior of the hinge; in the sake brevity, we will refer to this model as the IMK model. This material implements the Modified Ibarra-Medina-Krawinkler Deterioration Model with PeakOriented Hysteretic Response (Ibarra et al. 2005; Lignos and Krawinkler 2012). The input required to define this material is comprised of the parameters required to define the backbone curve and additional parameters to account for the cyclic deterioration of strength and stiffness. This approach provides an efficient way of modeling and controlling plastic hinge formation. However, a drawback to concentrated plasticity models is that axial force-moment interaction and axial force-stiffness interaction are separate from the element behavior. Further information and details on the development of the numerical models are available in De Jesus-Vega (2018).

\section{Models' calibration/validation}

Notice that the experimental data available consisted only of shake table tests, there was no quasi-static cyclic reversal tests performed. Therefore, we first developed the fiberbased model using available results from the material tests, the geometry provided, and recommended values for the reinforcing bars degradation parameters. These degradation parameters were then refined to match the experimental results, specifically the rupture episodes that first occurred at EQ8 and further episodes in EQ9. Once the fiber model is fully calibrated, it used to simulate the column response to quasi-static cyclic reversals, and the obtained hysteretic responses are used to calibrate the backbone curve (first obtained through a traditional moment-curvature analysis using the code CUMBIA-Montejo and Kowalsky 2007) and the degradation parameters for the IMK model. Further refinements to the IMK parameters are then performed to enhance the match of the model with the dynamic experimental data available. Figure 3 shows the hysteretic responses (moment-rotation and force-displacement) of the final models for two different load histories of cyclic reversals: (1) 3 cycles at target displacement ductilities 1 , 3,5 , and 7 and (2) single cycles at target displacement ductilities 3, 7, 3, 7, 3. Displacement ductility is defined as the ratio between the maximum lateral drift and the yield drift, and the reported experimental yield drift ratio of $1.23 \%$ was used in the ductility calculations. It is seen that despite the obvious differences in the shape of the hysteric loops, the peak loads reached and the strength and stiffness degradation exhibited by both models are quite similar. Nevertheless, the dynamic response of the column was better captured by the fibers model - specially at the earthquake loads that imposed the larger damage to the column. Figure 4 shows, for example, a comparison of the experimental and numerical models results for EQ8, and this is the load stage, where rupture of the longitudinal reinforcement was first induced. It is seen that while both models appropriately captured the peak displacement ductility experienced by the column, the lumped plasticity model predicted a substantial residual displacement that did not match the actual column response.
Fig. 3 Calibration of the cyclic degradation parameters. Top figures load history consisting of 3 cycles at target displacement ductilities 1, 3, 5, and 7 . Bottom figures: single cycles at target displacement ductilities 3 , $7,3,7$, and 3
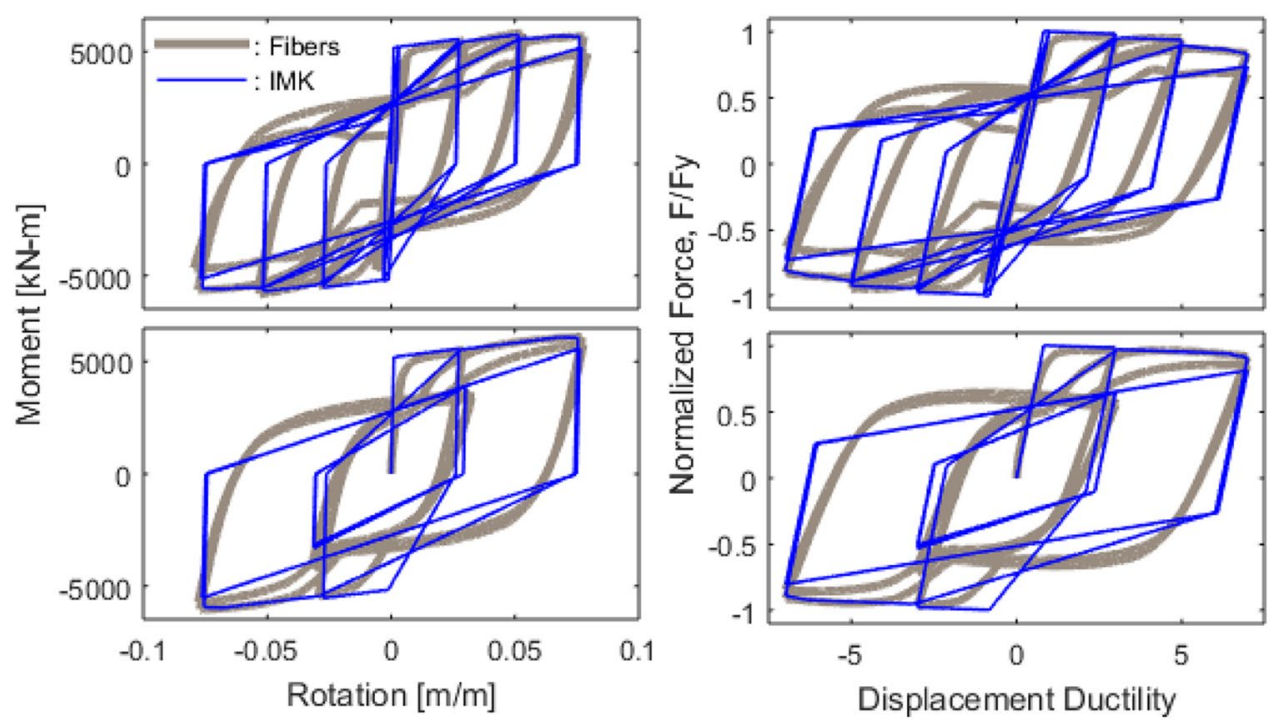
Fig. 4 Comparison of experimental and numerical models results for EQ8. Top: column accelerations, bottom: displacement ductilities

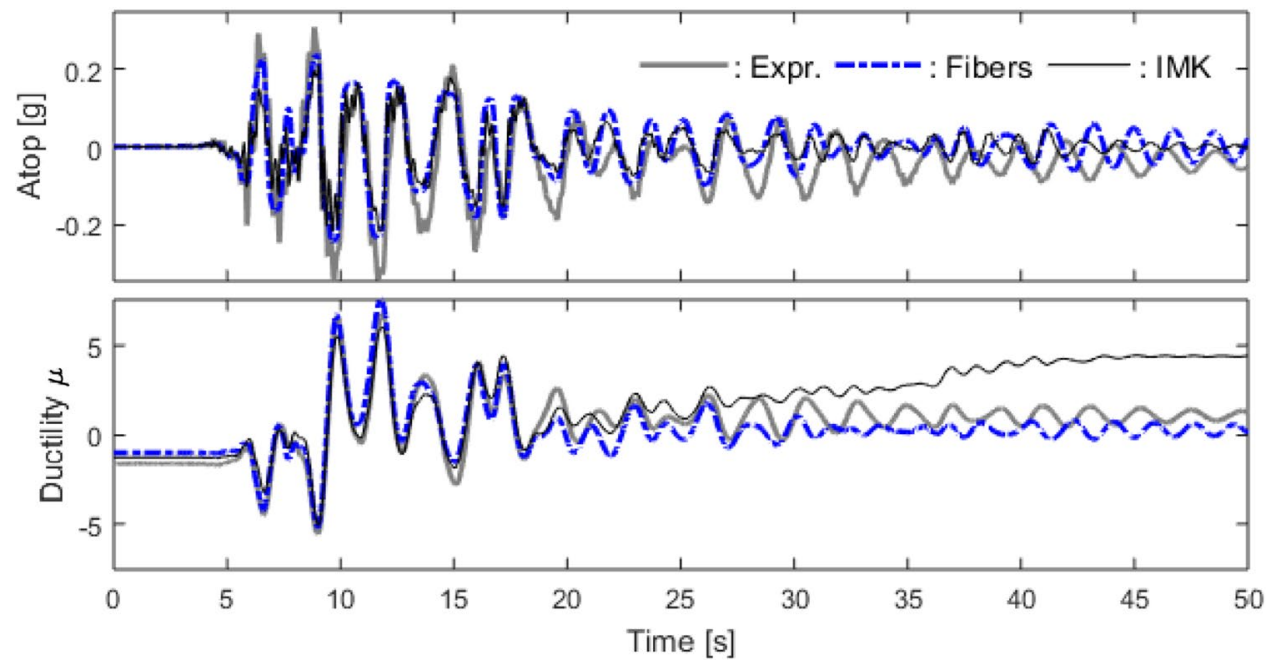

\section{$\mathrm{RC}$ bridge column models with reduced ductility capacity and strength}

The first model (original UCSD column) represented a modern structure designed for a zone with high seismic activity; therefore, it exhibited large levels of ductility capacity due mainly to a small separation between transverse steel reinforcement and the use of "seismic" reinforcing steel (i.e., longitudinal steel bars with notable strain hardening and large deformation capacity). The original column models are now modified, so that its ductility is significantly reduced compared to the first column. Most geometric characteristics: length, diameter, weight, and quantity of reinforcing steel bars were maintained constant. However, the diameter of the bars, the yield stress, and strain hardening is reduced, while the spacing between hoops is increased. By changing the reinforcing steel bar size to No. 9, we achieve a steel ratio of $1 \%$, compared to $1.55 \%$ in the ductile column. The constitutive relationship for the confined concrete was modified by changing the transverse reinforcement bar to No. 4 spaced at $0.61 \mathrm{~m}$ (24 in.), compared to double No. 5 hoops spaced $15.2 \mathrm{~cm}$ (6 in) in the ductile column. The degradation parameters controlling the longitudinal reinforcement response were also altered to increase the cyclic degradation rate. As for the first column, this second structure will be modeled using two approaches. The fiber-based model is the first to be generated, and in the absence of experimental data, the lumped plasticity model is calibrated to match the results from the fiber model. Figure 5 compares the hysteretic responses obtained for this column with the obtained for the original (ductile) column when the fiber approach is used.

\section{RC squat wall model (well detailed, original squat wall)}

As current fiber-based approaches have not reached the required maturity to capture shear deformations in a robust manner, the squat wall is modeled using the lumped plasticity approach only. Similar to the bridge column, the model parameters are calibrated using experimental data and the degradation parameters are then varied to analyze the effect of duration on different structural deterioration scenarios.
Fig. 5 Comparison of cyclic pushover results from the fiberbased models of the original and reduced ductility columns
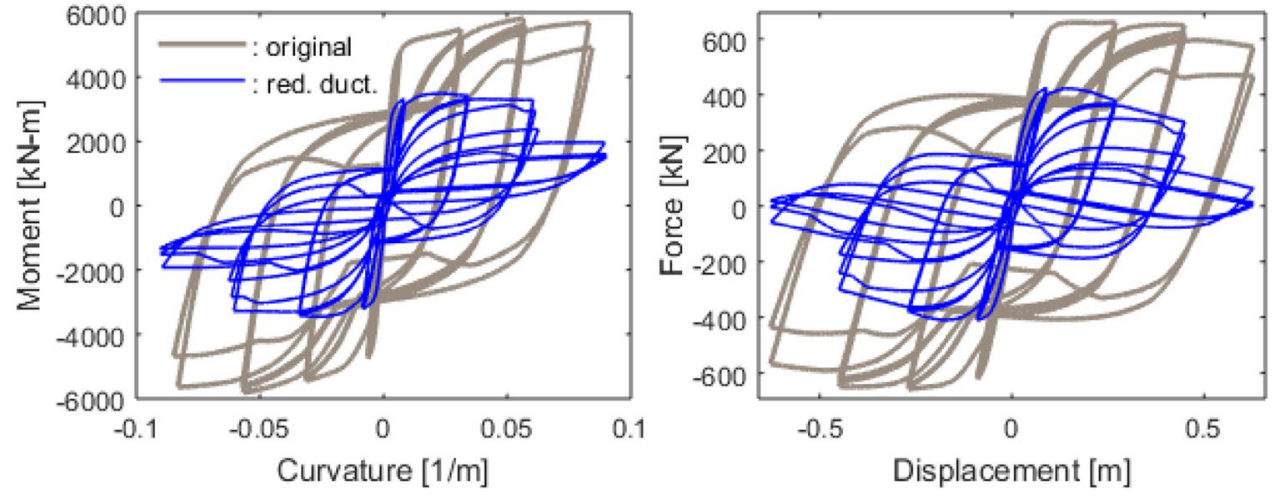


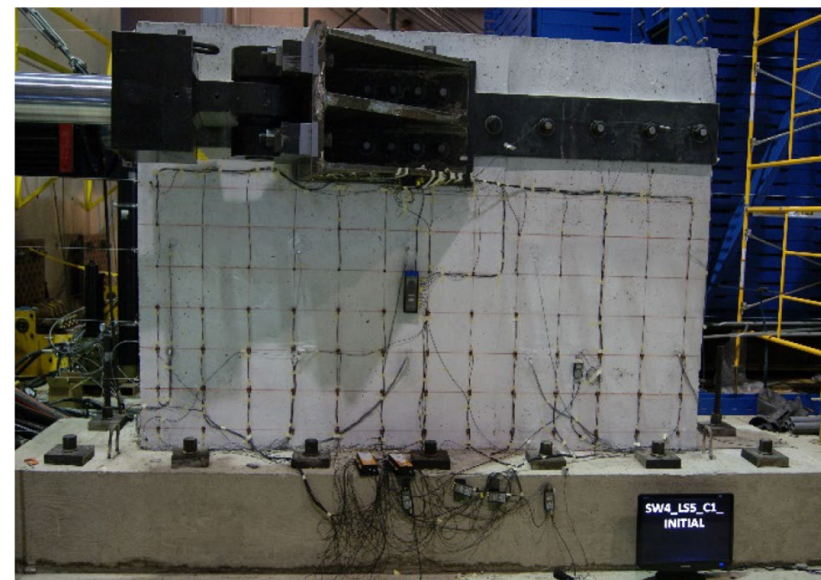

Fig. 6 Squat wall during cyclic reversals test. Photo taken from: https ://www.designsafe-ci.org/data/browser/public/nees.public//NEES2009-0676.groups

The experimental test used for calibration was part of a set of 12 squat rectangular RC walls tested at the University of New York at Buffalo (UB) under static cyclic loads (Luna et al. 2013, Fig. 6). The selected squat wall was $3.302 \mathrm{~m}$ $(10.83 \mathrm{ft})$ in height, $3.048 \mathrm{~m}(10 \mathrm{ft})$ in width, and $20 \mathrm{~cm}$ (7.87 in.) in thickness. The reported concrete compressive strength was $24.8 \mathrm{MPa}$ and the reinforcement consisted of horizontal and vertical bars with a reinforcement ratio $(\rho)$ of 0.67 in each direction. No axial load was applied.

The IMK-Pinching model approach was used rather than the IMK-PeakOriened used for the column, as it captures the key features of squat walls response: strength and stiffness deterioration and pinched hysteresis (Gulec and Whittaker 2009). Utilizing the force-displacement data available from the experimental test, we approximated a backbone curve (moment-rotation) from where the required key points needed to define the model are initially estimated. The degradation parameters are set to match the registered hysteretic response. Figure 7 compares the results from the calibrated model with the experimental data.

\section{RC squat wall model with reduced displacement capacity}

This model was generated based on the same geometrical properties of the original wall model. The reduction in displacement capacity was achieved by changing the degradation parameters and post-capping slope on the backbone curve. Figure 8 compares the cyclic lateral behavior for both walls for different load protocols: 3 cycles at target drifts of $0.05,0.010,0.015,0.020$, and 0.025 and single cycles at target drifts of $0.01,0.025,0.01,0.025$, and 0.01 . It is seen that the reduced ductility wall exhibits the same yield strength;

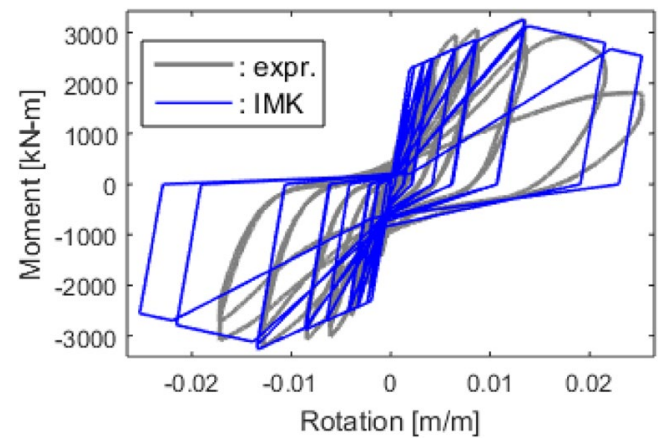

Fig. 7 Comparison of experimental and numerical models results for the squat wall

however, the displacement capacity is severely reduced as a result of the increased stiffness and strength deterioration. In the absence of experimental dynamic data, both walls were subjected to the same dynamic load protocol and the UCSD column was subjected to. The mass in top of the wall used for the dynamic analyses was set, so that the resulting axial load ratio was $20 \%$. The results obtained show that the reduced ductility wall failed at the third excitation (Fig. 9), whereas the original wall lasted up to the sixth excitation. Further details on the development of the numerical models are available in De Jesus-Vega (2018).

\section{Seismic input}

The numerical models previously described will be used to assess the influence of strong motion duration on inelastic response. To accomplish this, sets of 20 short strong motion duration acceleration time series are generated with records made spectrally equivalent to a target long-duration record. By spectrally equivalent, we mean that the short records are modified, so that their 5\% damping pseudo-acceleration response spectrum match the response spectrum of the longduration record used as target in each set.

\section{Database of long-duration records}

The first step to generate these sets was to construct a database of long-duration records. A large number of recorded motions from different databases around the world were evaluated to select long-duration records suitable for nonlinear analysis. The criteria applied were similar to the implemented in Chandramohan (2016). The selected records shall have a peak ground acceleration (PGA) larger than $0.1 \mathrm{~g}$ and peak ground velocity (PGV) above $10 \mathrm{~cm} / \mathrm{s}$; moreover, the significant duration (D5-75, time interval over which 5\% and $75 \%$ of the squared acceleration is accumulated) shall reach at least $20 \mathrm{~s}$. In the case that both horizontal directions 
fulfilled the PGA and PGV criteria, the component with the larger duration was selected. We use D5-75 as this is the preferred duration definition used in earthquake engineering research and practice (e.g., Chandramohan 2016; Montejo and Vidot-Vega 2017). Figure 10 shows the distribution of duration as a function of the PGA and cumulative absolute velocity (CAV) for the 119 records selected. It is seen that D5-75 values are in the interval $\sim(20-80) \mathrm{s}$ and CAV values are in the interval $\sim(5-280) \mathrm{g} \mathrm{s}$, with most of the largest duration records concentrating around a CAV of $\sim 40 \mathrm{~g} \mathrm{~s}$ and a PGA of $\sim 0.4 \mathrm{~g}$.

\section{Target long-duration records}

From the database of 119 long-duration records previously described, we selected records with important spectral
Fig. 8 Comparison of the hysteretic responses of the original and reduced displacement capacity walls for different load protocols. Left: 3 cycles at target drift of 0.05, 0.010, 0.015, 0.020 , and 0.025 . Right: single cycles at target drift of 0.01 , $0.025,0.01,0.025$, and 0.01
Fig. 9 Response (acceleration and drift time histories) of the original and reduced displacement wall models when subjected to EQ3
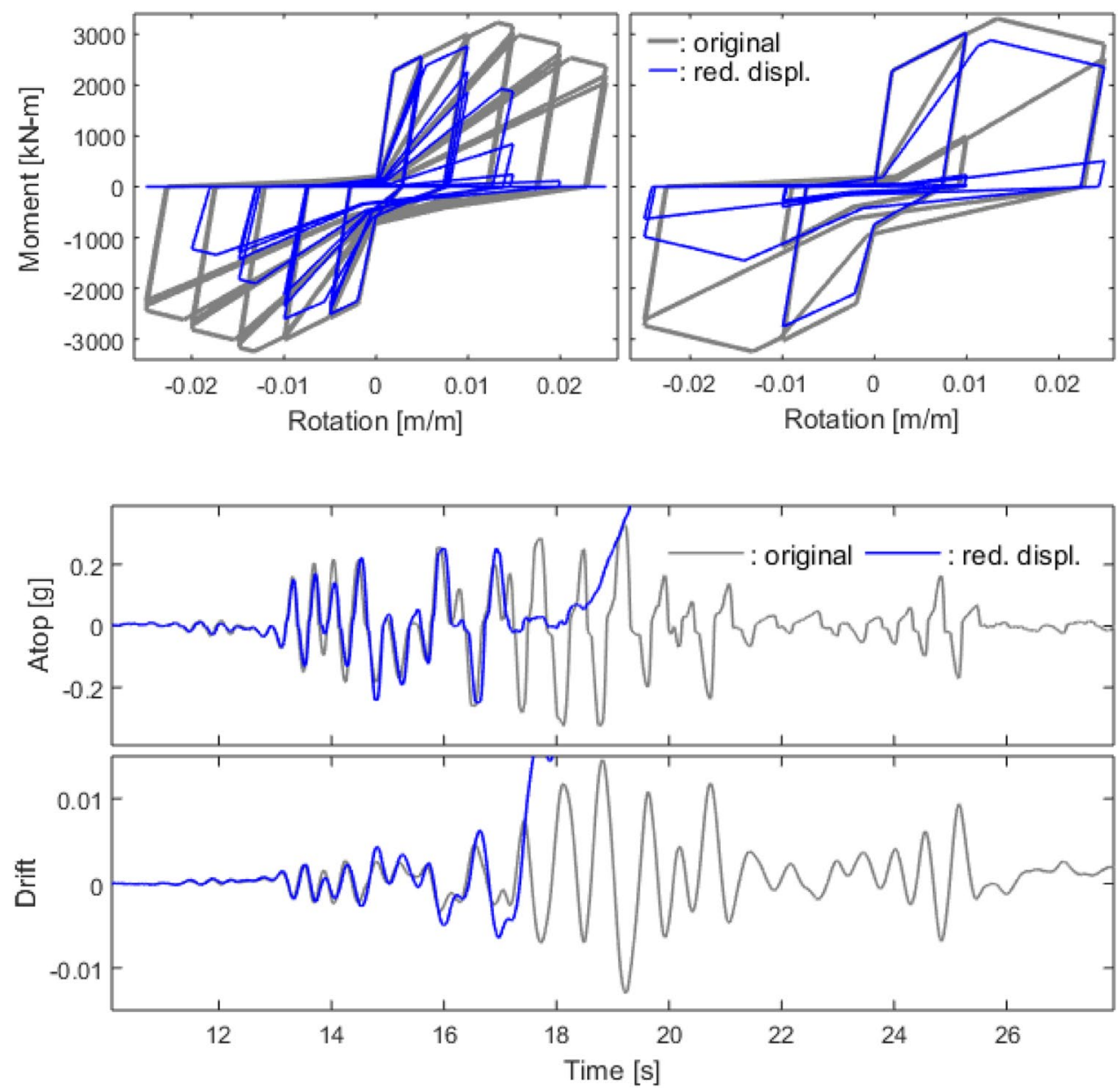

Fig. 10 Distribution of significant duration (D5-75) in the long-duration data set as a function of the records peak ground acceleration (PGA) and cumulative absolute velocity (CAV)
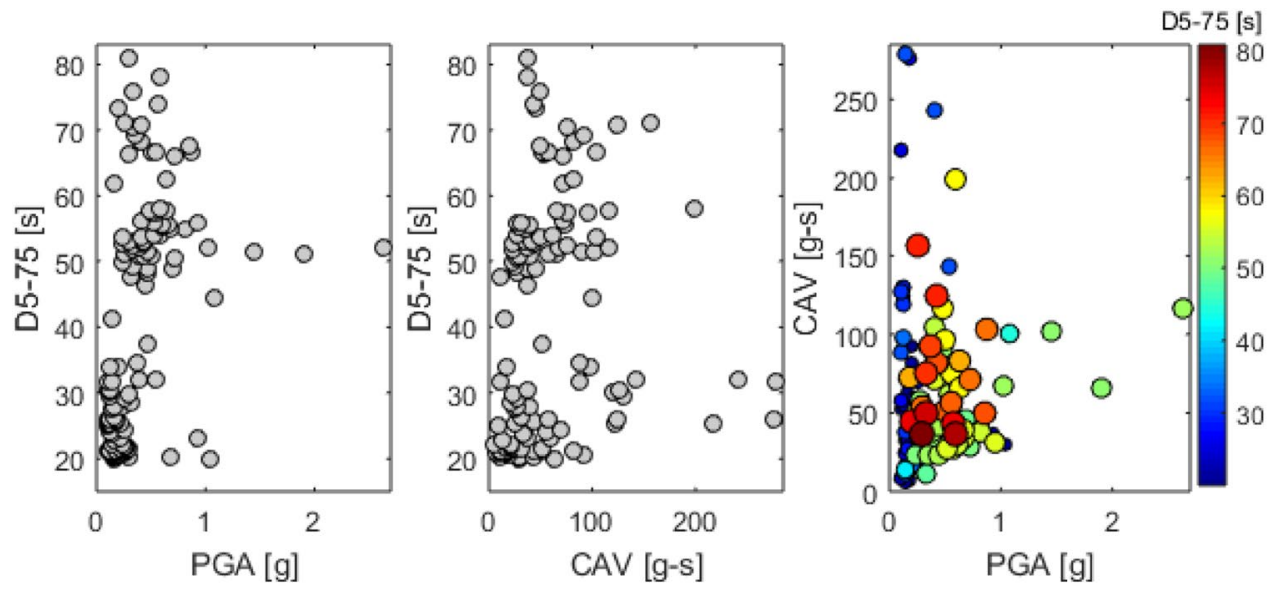
amplification in the range of natural periods exhibited by the column, so that significant shaking is induced to the structure. This period range was estimated from preliminary nonlinear analyses of the columns at different levels of intensity. Figure 11 shows the change in natural period at different levels of ductility demand. It is seen that there is a significant elongation in the natural period up to ductility 1 ; however, for increasing levels of ductility, the increase in the natural period is less noticeable. Moreover, since both columns share the same geometry, their natural periods are similar. Based on these results, a period range between $0.7 \mathrm{~s}$ and $1.5 \mathrm{~s}$ is used to evaluate the spectral amplitude of the long-duration records. Table 1 summarizes the 10 target long-duration records selected, and Fig. 12 presents their $5 \%$ damping pseudo-acceleration response spectra.

\section{Sets of short-duration spectrally equivalent records}

The seed motions used to generate the spectrally equivalent records were selected based on the resemblance of
Fig. 11 Natural periods as a function of the induced inelastic demand for the ductile column (left) and reduced ductility column (right)
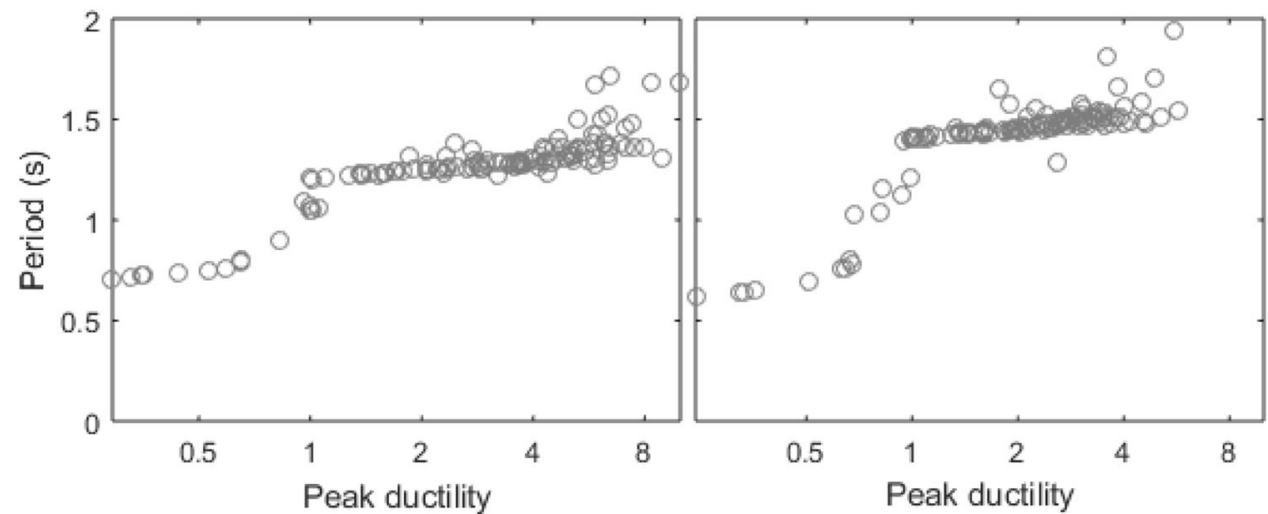

Table 1 Set of long-duration records

\begin{tabular}{|c|c|c|c|c|c|c|c|c|c|}
\hline Earthquake name & Magnitude & Station name & Tag & Database & PGA (g) & $\mathrm{PGV}(\mathrm{cm} / \mathrm{s})$ & PGD $(\mathrm{cm})$ & CAV (g s) & D5-75 (s) \\
\hline Chi Chi & 7.62 & TCU111 & EQ14 & PEER NGA-West2 & 0.13 & 53.29 & 49.80 & 129.52 & 29.4 \\
\hline Chi Chi & 7.62 & CHY107 & EQ13 & PEER NGA-West 2 & 0.10 & 21.34 & 14.61 & 88.06 & 31.5 \\
\hline Maule & 8.80 & HUALANE S/N 4564 & EQ22 & CESMD EDC & 0.38 & 38.83 & 4.84 & 86.99 & 34.5 \\
\hline Amberley & 7.80 & Waikari & EQ114 & CESMD EDC & 0.15 & 13.68 & 36.66 & 14.45 & 41.3 \\
\hline Tohoku & 9.00 & MYG010 & EQ53 & NIED K/KiK-net & 0.48 & 49.49 & 13.88 & 116.05 & 57.7 \\
\hline Tohoku & 9.00 & MYG006 & EQ52 & NIED K/KiK-net & 0.58 & 89.16 & 26.86 & 199.44 & 58.1 \\
\hline Amberley & 7.80 & Glyn Wye & EQ96 & CESMD EDC & 0.17 & 17.97 & 46.44 & 72.58 & 61.9 \\
\hline Tohoku & 9.00 & MYG016 & EQ68 & NIED K/KiK-net & 0.42 & 51.19 & 10.71 & 81.45 & 68.3 \\
\hline Tohoku & 9.00 & MYG017 & EQ57 & NIED K/KiK-net & 0.36 & 45.97 & 11.69 & 92.69 & 69.3 \\
\hline Tohoku & 9.00 & MYG015 & EQ69 & NIED K/KiK-net & 0.42 & 74.12 & 26.77 & 124.72 & 70.6 \\
\hline
\end{tabular}

Fig. $125 \%$ pseudo-acceleration spectra for the 10 long-duration records selected as target for the analysis. Left: original spectra. Right: spectra normalized to a maximum amplitude of 1 . The vertical lines denote expected range of natural periods for the columns
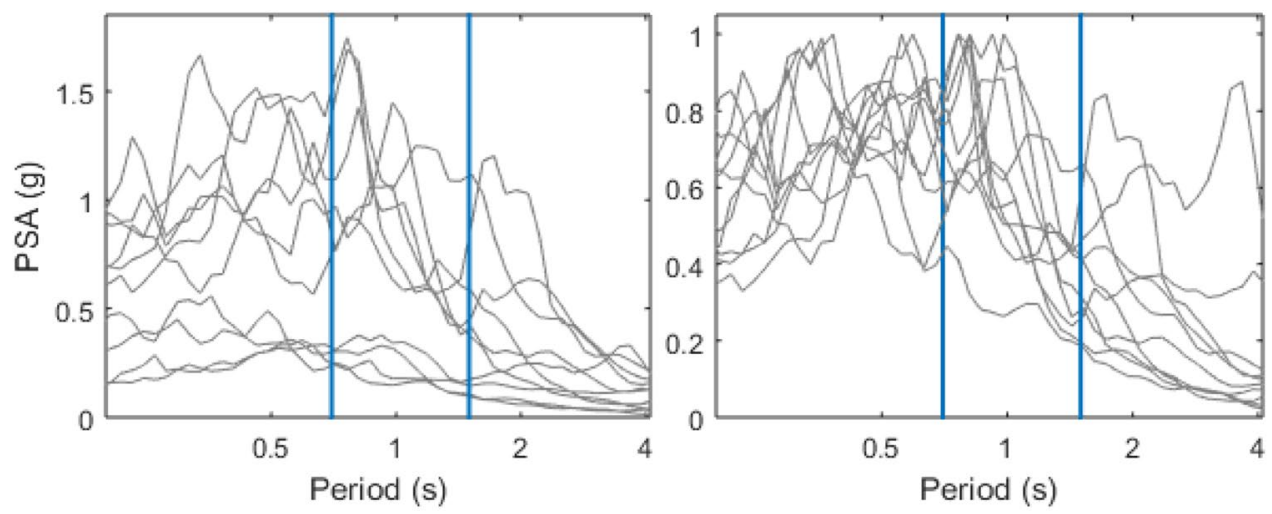
their response spectra with the target spectrum, i.e., the response spectrum from the long-duration record. The spectral matching was accomplished using the code ArtifQuakeLetII (Montejo and Suarez 2013). This code implements an algorithm based on the Continuous Wavelet Transform (CWT) which decomposes the seed record into detail functions (i.e., functions with a very dominant frequency and modulated amplitude) and reconstructs the signal through an iterative procedure that independently scales; these functions to obtain an average match with the target spectrum. This methodology has been shown to preserve the main characteristics of the seed records (e.g., Perez-Rivera and Montejo 2017; Chi-Miranda and Montejo 2017). Figure 13 presents a comparison between response spectra and time histories of a spectrally equivalent short-duration record and its corresponding target (i.e., the long-duration record). The long-duration record presented is from the 2011 Tohoku earthquake, recorded at the MYG015 station and with a significant duration
(D5-75) of $70.6 \mathrm{~s}$. The spectrally equivalent short-duration record was generated using the 2011 Christchurch earthquake at the Christchurch Cathedral College station (RSN8064) as seed, and the resulting record has a significant duration (D5-75) of $4.6 \mathrm{~s}$. It seen that despite the large difference in the duration, the modified short-duration record matches quite well the long-duration record spectrum. Figure 14 shows the response spectra and D5-75 for the set of 20 records generated for Tohoku earthquake at MYG017. It is seen that an acceptable match is obtained for all the spectrally equivalent records generated. Nevertheless, it is also noticed that during the matching process, the strong motion duration of some seed records was significantly increased, reaching values above $20 \mathrm{~s}$. To account for this, in the upcoming structural analyses, the results from the 11 shorter records are treated separately and compared with the results from the whole set of 20 records. Similar results were obtained for the other 9 sets and are available elsewhere (De Jesus-Vega 2018).
Fig. 13 Example of one of the short-duration spectrally equivalent records generated
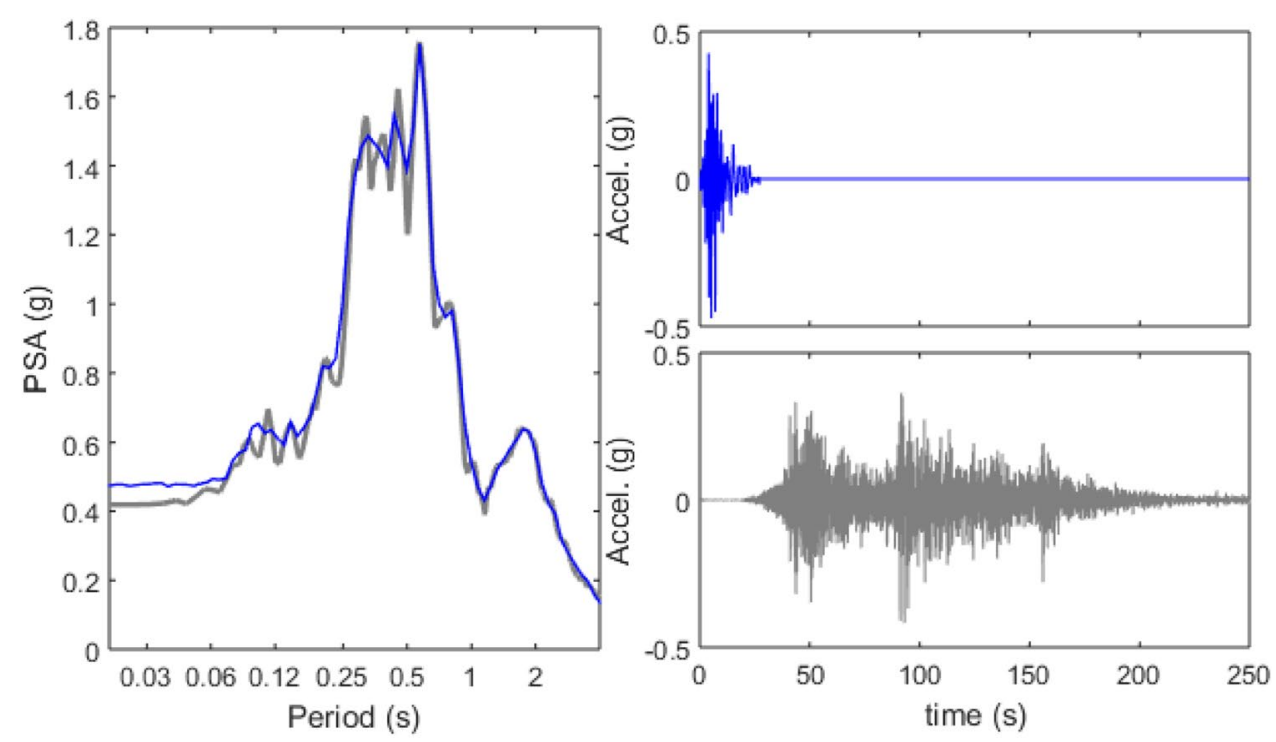

Fig. 14 Set of 20 short-duration spectrally equivalent records for the 2011 Tohoku Eq. at MYG017. Left: pseudo-acceleration response spectra for the target (thick line, long-duration record) and the set of shortduration spectrally equivalent records (thin lines). Right: strong motion duration values, the horizontal lines denote the average duration of the 11 shortest records and for the whole set
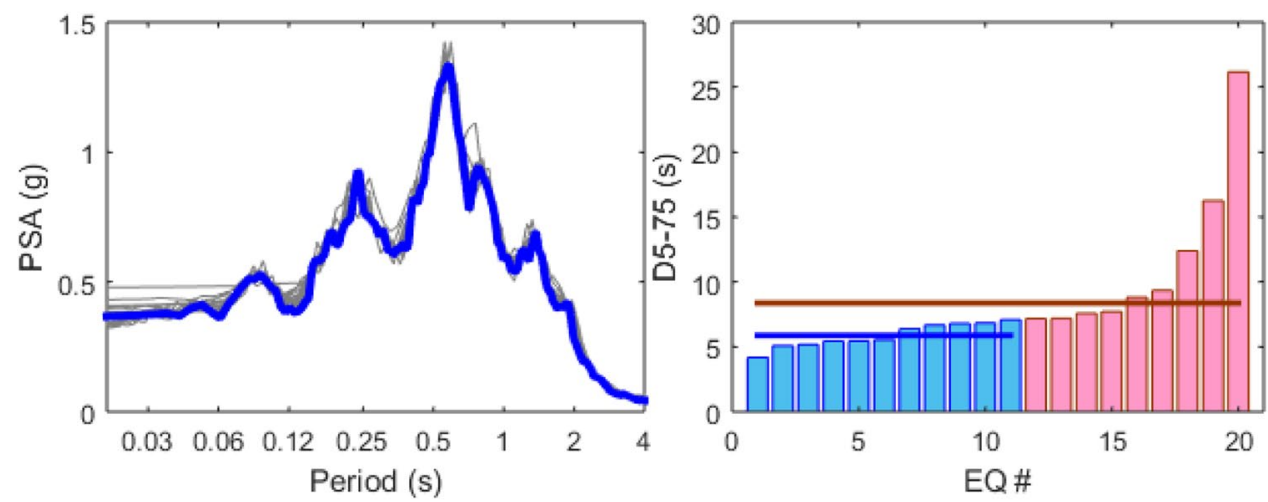


\section{Duration effects on the inelastic response of RC bridge columns}

A series of IDA analyses is performed by applying a set of 12 scaling factors to each target long-duration record and its corresponding set of 20 short-duration spectrally equivalent records. The scaling factors are set, so that the structure undergoes the desired range of structural performance, from elastic response to severe damage. The 252 scaled records per target long-duration record ( 240 from the short-duration set and 12 from the corresponding long-duration target) are used as input for the time-history analyses; from each analysis, the peak displacement ductility and the average peak displacement ductility (average from the peak ductility in each direction) are retrieved. The same procedure is implemented for 10 target longduration records and the 4 column models (fibers ductile, fiber-reduced ductility, IMK ductile, and IMK-reduced ductility). A total of 10,080 nonlinear analyses were performed ( 10 sets $* 21$ records/set $* 12$ scale factors $* 4$ models). This produced an overwhelming amount of data; some representative results are presented in Figs. 15, 16,
17 , and 18 . The totality of the results obtained can be accessed from De Jesus-Vega (2018).

Figure 15 shows the results obtained for EQ69 (SD5$75=70.6 \mathrm{~s}$ ) and its corresponding set of 20 short-duration spectrally equivalent records (average SD5-75 $=9.6 \mathrm{~s}$ ) for the fiber model of the ductile column. It is seen that the long-duration record seems to impose larger peak inelastic demands for ductility levels below 5 ; after this point, the differences are reduced. For the average peak ductility demand (average from both directions), the differences between both IDA curves are less significant. Nevertheless, when the same model is subject to the EQ96 scenario (SD5-75 =61.9 s), it is seen that the short records (average SD5-75 $=9.3 \mathrm{~s}$ ) consistently impose larger inelastic demands (Fig. 16). When the same pair of set records are applied to the reduced ductility column (Figs. 17 for EQ69 and 18 for EQ96), the results follow the same trend: for the EQ69 case, the long record imposed the larger demands, and for EQ96, the short records do. However, in the EQ69 scenario, the control of the long record is more consistent than for the ductile column, covering all the range of ductilities studied and increasing as the inelastic demand increases. Similar results were obtained for the IMK model and are not shown here in the sake of brevity.
Fig. 15 IDA results for the ductile column (fiber models) subjected to EQ69 and its corresponding set of 20 spectrally equivalent records: individual results for each short record (circle markers), its average (thick black line) and average \pm SD (dashed lines), and the response for the (target) long-duration record (blue line). Long record SD5-75 $=70.6 \mathrm{~s}$, short records set average SD5$75=9.6 \mathrm{~s}$
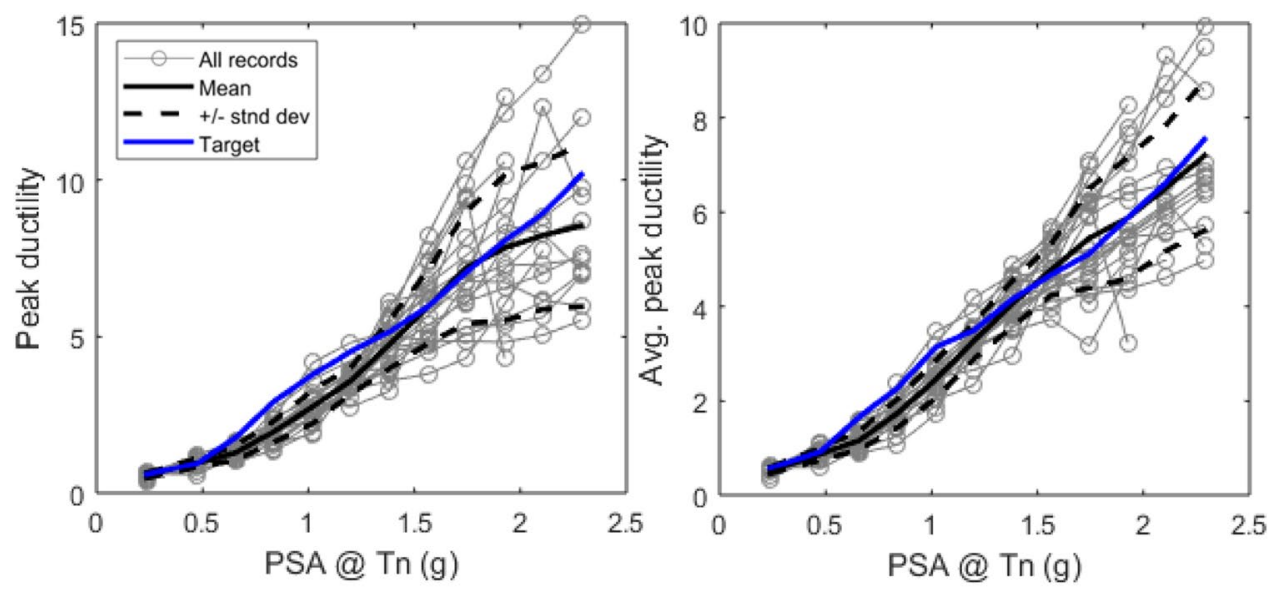

Fig. 16 IDA results for the ductile column (fiber models) subjected to EQ96 and its corresponding set of 20 spectrally equivalent records: individual results for each short record (circle markers), its average (thick black line) and average $\pm \mathrm{SD}$ (dashed lines), and the response for the (target) long-duration record (blue line). Long record SD5-75 $=61.9 \mathrm{~s}$, short records set average SD5$75=9.3 \mathrm{~s}$
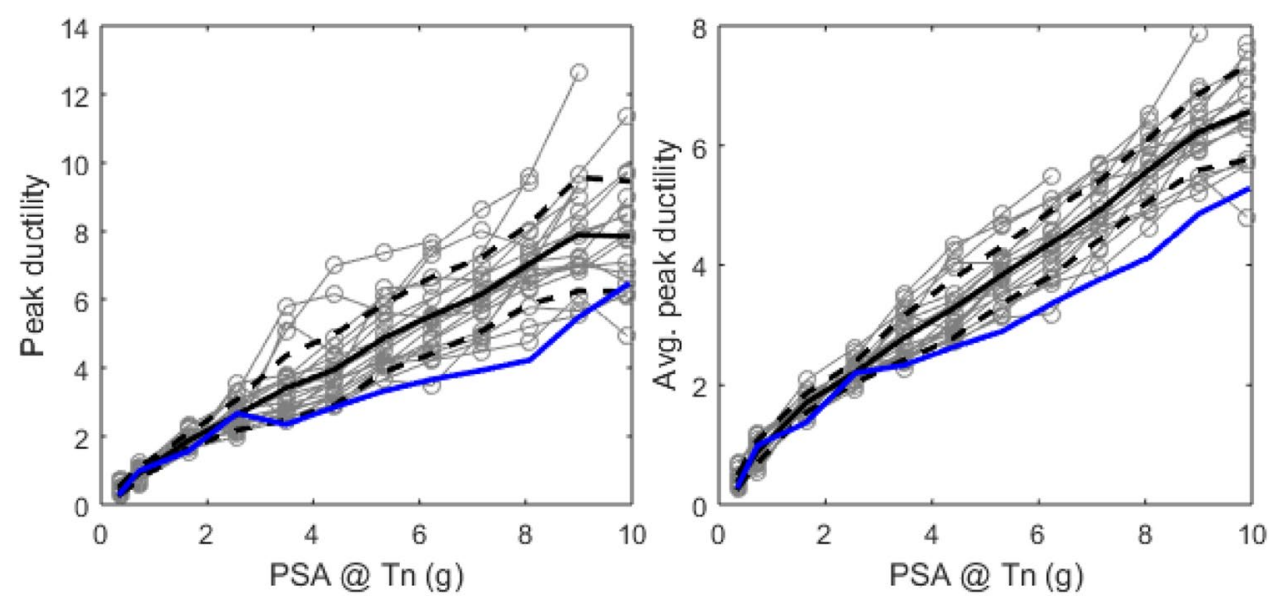
Aiming to quantify the duration effect, we proceed to take ratios between the ductility demand induced by the longduration record and the average-induced ductility demand from its corresponding short-duration set. A sample of the results is presented in Figs. 19 and 20 for the fiber-based and IMK models, respectively. The results presented correspond
Fig. 17 IDA results for the reduced ductility column (fiber models) subjected to EQ69 and its corresponding set of 20 spectrally equivalent records: individual results for each short record (circle markers), its average (thick black line) and average $\pm \mathrm{SD}$ (dashed lines), and the response for the (target) long-duration record (blue line). Long record SD5-75 $=70.6 \mathrm{~s}$, short records set average SD5$75=9.6 \mathrm{~s}$

Fig. 18 IDA results for the reduced ductility column (fiber models) subjected to EQ96 and its corresponding set of 20 spectrally equivalent records: individual results for each short record (circle markers), its average (thick black line) and average $\pm S D$ (dashed lines), and the response for the (target) long-duration record (blue line). Long record SD5-75 $=61.9 \mathrm{~s}$, short records set average SD5$75=9.3 \mathrm{~s}$

Fig. 19 Ductility ratios: target (long-duration record)/average from the short-duration set. Black lines denote the ratios based on peak ductility and the blue lines the ratios based on average peak ductility, continuous lines used the average of the whole short-duration set and dashed lines the average of the 11 shortest records. a Ductile column with fiber model subjected to EQ69 set, b ductile column with fiber model subjected to EQ96 set, $\mathbf{c}$ reduced ductility column with fiber model subjected to EQ69 set, and $\mathbf{d}$ reduced ductility column with fiber model subjected to EQ96 set
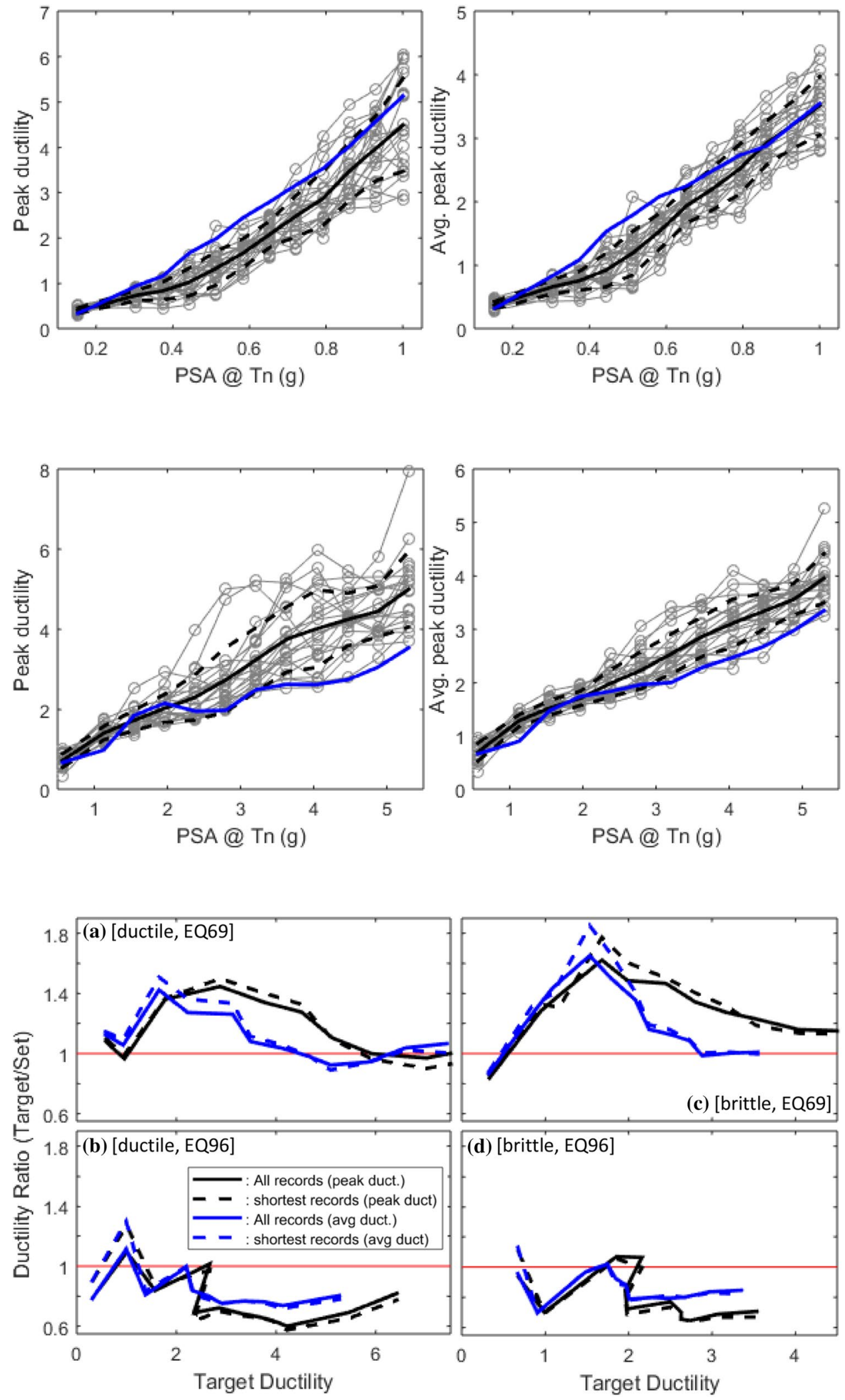
Fig. 20 Ductility ratios: target (long-duration record)/average from the short-duration set. Black lines denote the ratios based on peak ductility and the blue lines the ratios based on average peak ductility, continuous lines used the average of the whole short-duration set and dashed lines the average of the 11 shortest records. a Ductile column with IMK model subjected to EQ69 set, b ductile column with IMK model subjected to EQ96 set, c reduced ductility column with IMK model subjected to EQ69 set, and $\mathbf{d}$ reduced ductility column with IMK model subjected to EQ96 set

Fig. 21 Ductility ratios: target (long-duration record)/average from the short-duration set. Black lines denote the ratios based on peak ductility, and the blue lines denote the ratios based on average peak ductility, continuous lines used the average of the whole short-duration set, and dashed lines denote the average of the 11 shortest records. a Original wall subjected to EQ69 set, b original wall subjected to EQ68 set, c reduced displacement capacity wall subjected to EQ69 set, and d reduced displacement capacity wall subjected to EQ68 set
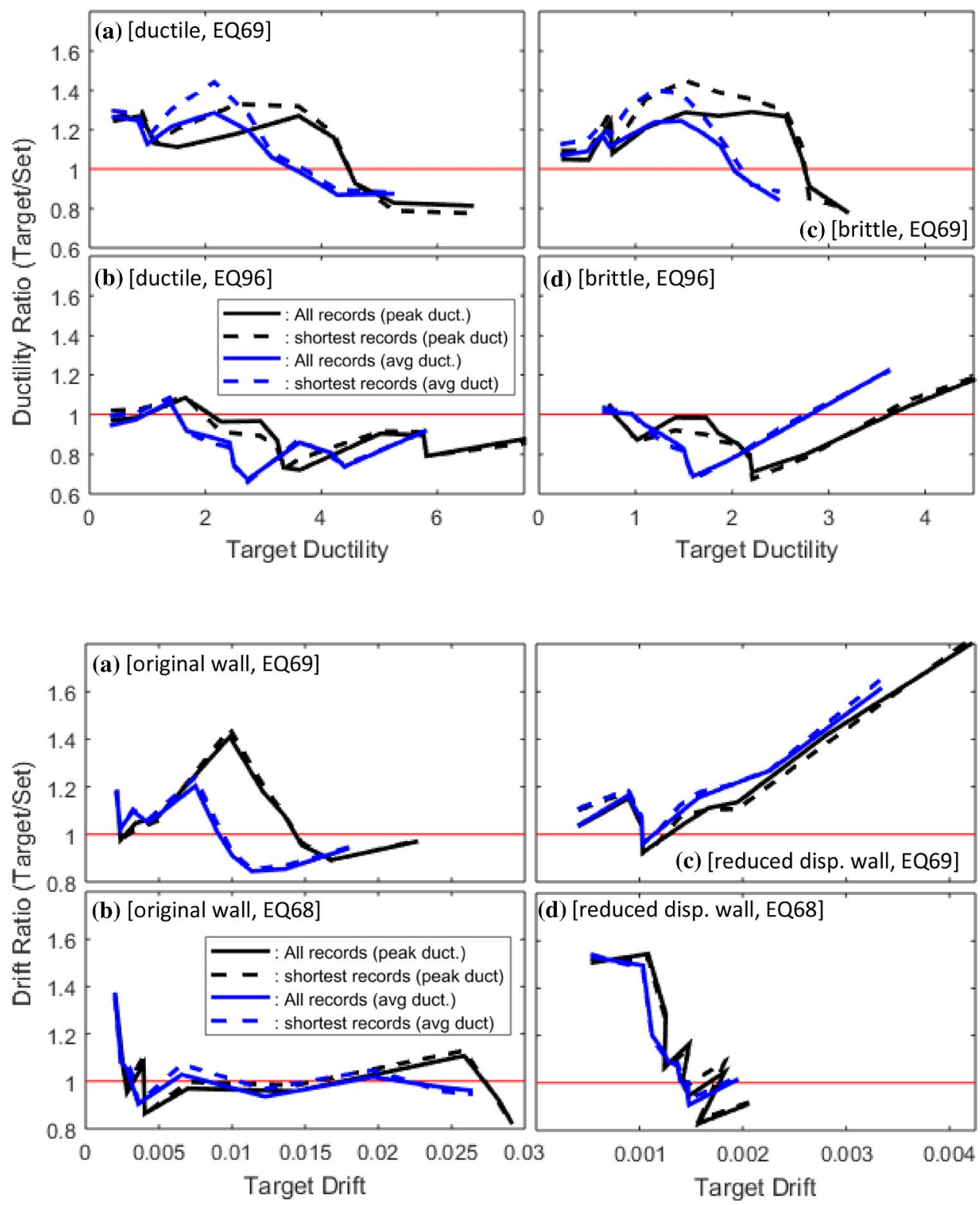

(d) [reduced disp. wall, EQ68]

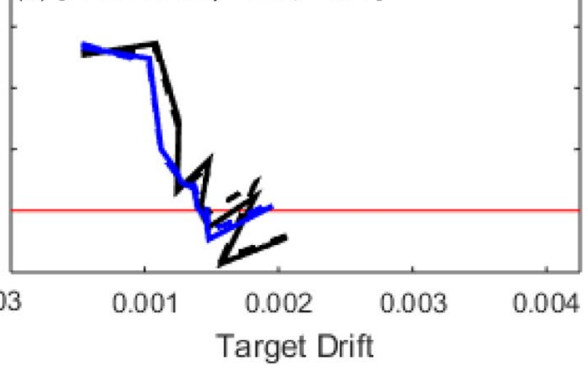

to the ductile and reduced ductility columns subjected to the sets for EQ69 and EQ96 scenarios. Figure 19 shows that the larger differences in the inelastic demands are exhibited by the brittle column. When subjected to EQ69, the short-duration set can underestimate the actual ductility demand by $65 \%$ based on the entire 20 records set or by $85 \%$ based on the 11 shortest records in the set. However, it is also noticed that the effect depends heavily on other characteristics of the input motion, since for EQ96, the short record set actually impose larger demands than the long record. Moreover, it is noticed that the differences in the induced ductility demand vary with the level of inelastic action. While in the elastic range, the differences in the lateral demands are minimal, the lager differences appear around the target ductility range $\sim 1-4$ and tend to disappear at target ductility levels above 5 .
The same behavior is observed when the columns are modeled using the IMK approach; however, the observed differences in the inelastic demands are larger when the column was modeled the fiber approach.

\section{Duration effects on the inelastic response of RC shear walls}

An IDA approach is also implemented to study the duration effects on the seismic response of RC shear walls. The input motions used, target long records, and sets of short spectrally equivalent records are the same used to investigate the duration effects on the RC bridge columns. Similar to the bridge column test, one model representative of 
a well-detailed structural element is first developed and calibrated using experimental data. A second model is then generated by changing the degradation parameters to obtain a model representative of a poor detailed structural element with reduced displacement capacity. Different from the column case, both models are implemented using the lumped plasticity IMK approach only, i.e., the distributed plasticity approach is not engaged for this case, as shear deformations are expected to be important. As for the column cases, to quantify the duration effect, we proceed to take ratios between the ductility induced by the long-duration record and the average from its corresponding spectrally equivalent short-duration set. A sample of the results is presented in Fig. 21, and it seen that the short-duration set can underestimate the actual lateral drift demand by up to $82 \%$ in the fragile wall at the largest lateral demand when subjected to the EQ69 scenario. However, when the same model is subjected to EQ68 scenario, the difference reaches 53\% at the early stages of the analysis (lower demands) and tends to disappear at larger lateral demands.

\section{Conclusions and final remarks}

This work was aimed to investigate the level of influence of strong motion duration on the inelastic demand of reinforced concrete structures. Figures 22 and 23 summarize the results obtained for both types of structural elements investigated. Figure 22 shows the induced ductility ratios (column cases) or drift ratios (shear wall cases) based on the average of the peak response from the records in each, while Fig. 23 shows
Fig. 22 Induced ductility or drift ratios (long-duration record/average from the shortduration set). a Ductile column with fibers model, $\mathbf{b}$ ductile column with IMK model, $\mathbf{c}$ reduced ductility column with fibers model, $\mathbf{d}$ reduced ductility column with IMK model, $\mathbf{e}$ original wall with IMK model, and $\mathbf{f}$ reduced displacement capacity wall with IMK model (a)

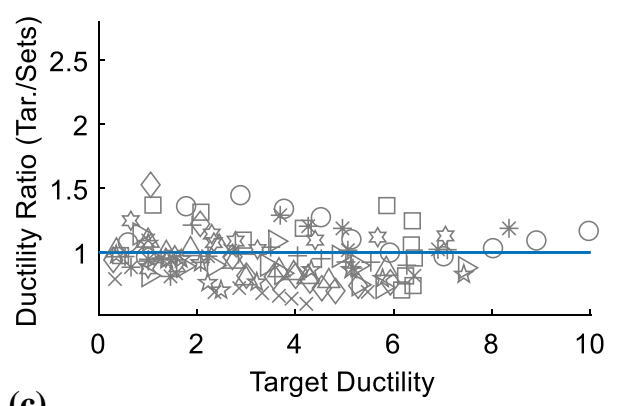

(c)

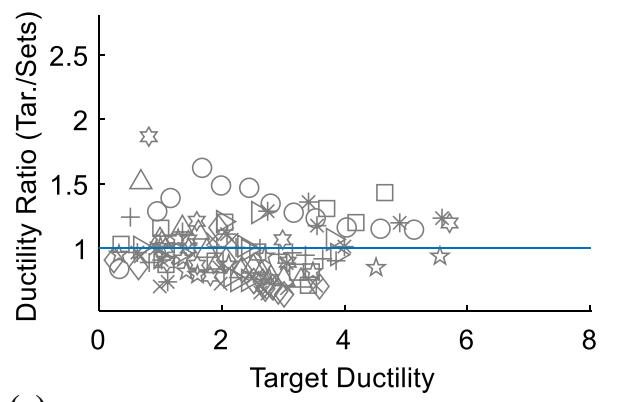

(e)

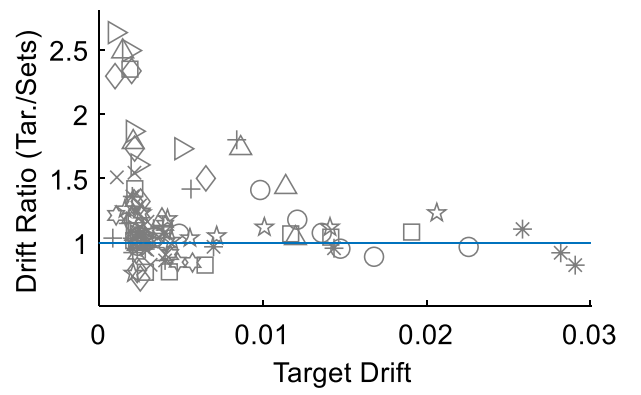

(b)

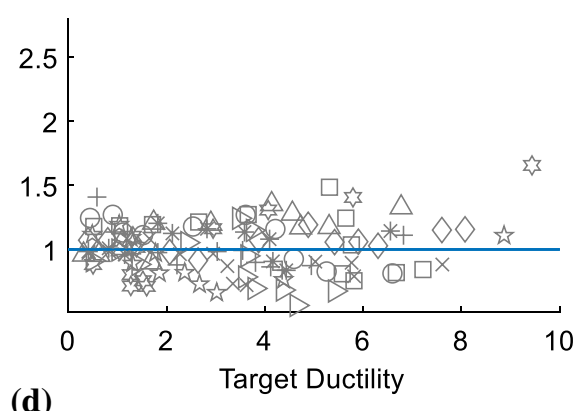

(d)

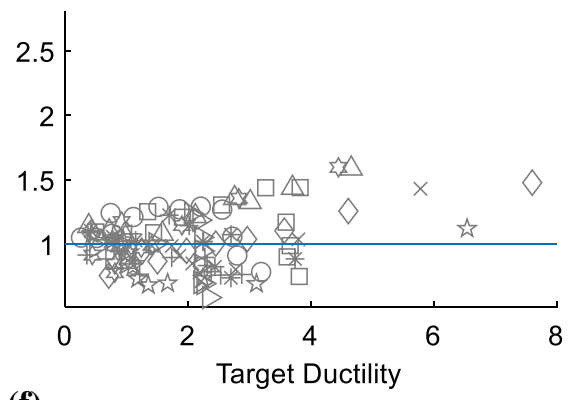

(f)

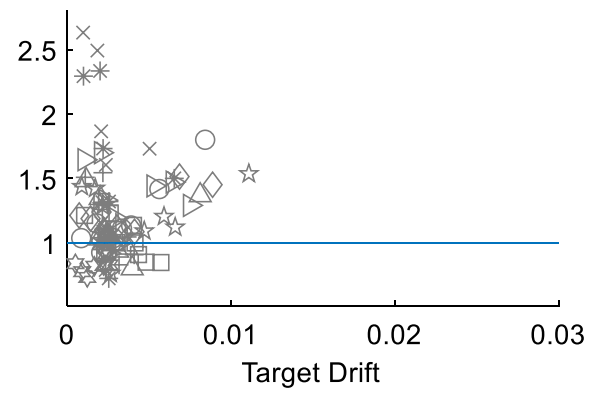


Fig. 23 Induced ductility or drift ratios (long-duration record/average from the 11 shortest records in each set). a ductile column with fibers model, b ductile column with IMK model, $\mathbf{c}$ reduced ductility column with fibers model, $\mathbf{d}$ reduced ductility column with IMK model, e original wall with IMK model, and $\mathbf{f}$ reduced displacement capacity wall with IMK model (a)

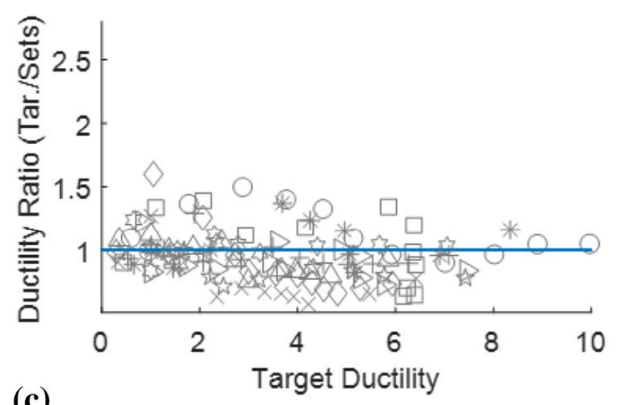

(c)

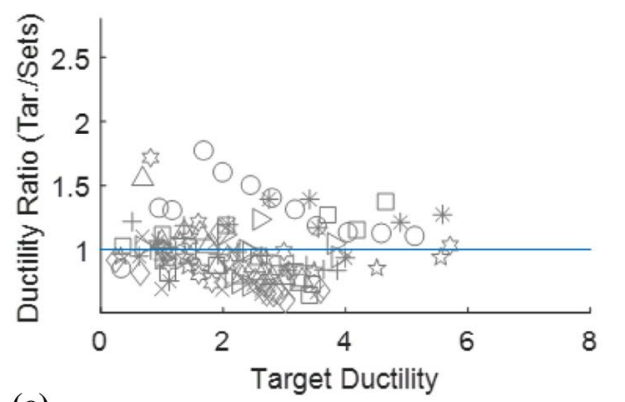

(e)

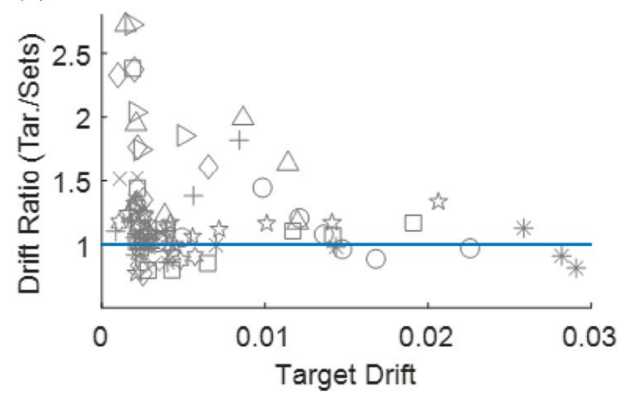

(b)

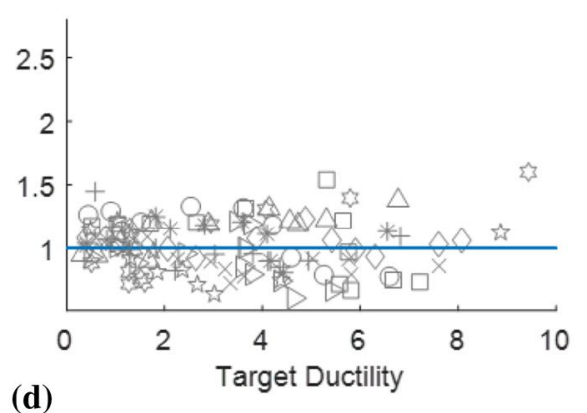

(d)

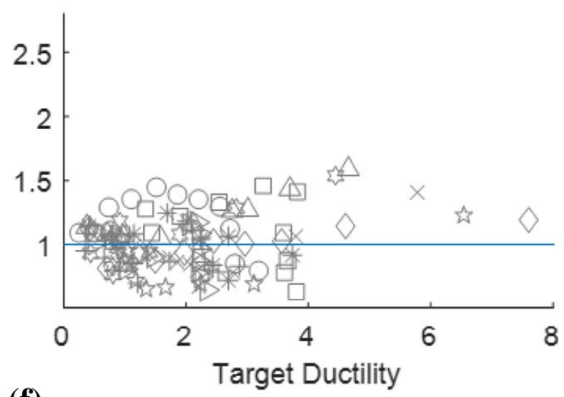

(f)

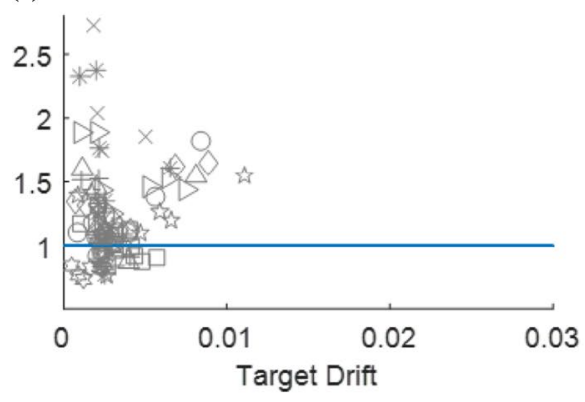

the same results if only the 11 shortest record in each set are used. From the results obtained, it can be concluded:

- Despite the overwhelming number of analyses performed and the simplicity of the structural models evaluated, a direct measure of the level of influence of strong motion duration on the inelastic demand of reinforced concrete structures is not possible due to the scatter on the results and the dependency on other factors. Overall, it was found that long-duration records tend to impose larger inelastic demands (Figs. 22, 23). However, such influence is difficult to quantify, as it was found to depend on the dynamic properties of the structure, the strength and stiffness degrading characteristics, and the approach used to generate the numerical model and the seismic scenario (target spectrum). While for some scenarios, the dominance of the long record was evident, there were some cases, where the set of short records clearly imposed larger demands than the target long record (e.g., see Fig. 18).

- Comparing the lateral demand ratios obtained for the column and wall models, it is apparent that duration seem to have a more harmful effect in the squat wall model than in the bridge column model. That is, the effect of large strong motion duration seems to be more detrimental in relatively rigid structures.

- Comparing the ratios obtained for the "well" versus the "poorly" detailed column, it is seen that duration have a larger detrimental effect on the "poorly" detailed column. However, for the wall cases, there are no major differences between the ratios obtained for the "well" and the "poor" detailed wall. It can be said that the duration effect would be augmented on poorly detailed structures if the structure is relatively flexible. However, in the case, 
where the structure is relatively rigid, and with an inherent reduced displacement capacity, the influence of the degradation parameters in the effect of duration seems negligible.

- The results obtained also show that the largest duration effect occurs at intermediate levels of lateral demand. As the lateral demand increases at levels associated with severe damage, the duration effect is reduced. An exception is noted when the reduced ductility column is modeled using the IMK approach, where some isolated large ratios appear at large levels of inelastic demand. However, this is likely due to limitations of the lumped plasticity model.

- The modeling approach may play an important role in the perceived effect of duration with the lumped plasticity multilinear hysteretic model, suggesting that the demands from the long records can be up to twice the inferred from the fiber models. This, despite the fact that all models were calibrated using the same sets of experimental results.

Acknowledgements This work was performed under awards NRCHQ-84-14-G-0057 and NRC-HQ-60-17-G-0033 from the US Nuclear Regulatory Commission. The statements, findings, conclusions, and recommendations are those of the authors and do not necessarily reflect the view of the US Nuclear Regulatory Commission.

Open Access This article is distributed under the terms of the Creative Commons Attribution 4.0 International License (http://creativeco mmons.org/licenses/by/4.0/), which permits unrestricted use, distribution, and reproduction in any medium, provided you give appropriate credit to the original author(s) and the source, provide a link to the Creative Commons license, and indicate if changes were made.

\section{References}

Aguirre DA, Gaviria CA, Montejo LA (2013) Wavelet-based damage detection in reinforced concrete structures subjected to seismic excitations. J Earthq Eng 17(8):1103-1125

Barbosa AR, Ribeiro FL, Neves LA (2017) Influence of earthquake ground-motion duration on damage estimation: application to steel moment resisting frames. Earthq Eng Struct Dyn 46(1):27-49

Bravo-Haro MA, Elghazouli AY (2018) Influence of earthquake duration on the response of steel moment frames. Soil Dyn Earthq Eng 115:634-651

Building Seismic Safety Council (BSSC) (2015) NEHRP recommended seismic provisions for new buildings and other structures, FEMA P-1050-1, Washington, DC

Chandramohan R (2016) Duration of earthquake ground motion: influence on structural collapse risk and integration in design and assessment practice. Ph.D. thesis. Stanford University

Chandramohan R, Baker JW, Deierlein GG (2017) Physical mechanisms underlying the influence of ground motion duration on structural collapse capacity. In: Proceedings of the 16th world conference on earthquake engineering, Santiago Chile

Chi-Miranda MA, Montejo LA (2017) A numerical comparison of random vibration theory and time histories-based methods for equivalent-linear site response analyses. Int J Geo-Eng 8(1):22

De Jesus-Vega E (2018) Strong motion duration influence on nonlinear seismic response. MS thesis, University of Puerto Rico at Mayaguez, Mayaguez, PR

Gulec CK, Whittaker AS (2009) Performance-based assessment and design of squat reinforced concrete shear walls, $p$ 291. MCEER

Hancock J, Bommer JJ (2006) A state-of-knowledge review of the influence of strong motion duration on structural damage. Earthq Spectra 22(3):827-845

Ibarra LF, Medina RA, Krawinkler H (2005) Hysteretic models that incorporate strength and stiffness deterioration. Earthq Eng Struct Dyn 34(12):1489-1511

Lignos DG, Krawinkler H (2012) Development and utilization of structural component databases for performance-based earthquake engineering. J Struct Eng 139(8):1382-1394

Luna B, Rivera J, Rocks J, Goksu C, Weinreber S, Whittaker A (2013) University at buffalo-low aspect ratio rectangular reinforced concrete shear wall-specimen SW1. Network for earthquake engineering simulation, dataset. https://doi.org/10.4231/d32b8vb8x

McKenna F, Scott M, Fenves GL, Jeremic B (2000) Open system for earthquake engineering simulation-OpenSees. http://www.opens ees.berkeley.edu

Mohle J, Kunnath S (2006) Reinforcing steel material. http://opens ees.berkeley.edu

Molazadeh M, Saffari H (2018) The effects of ground motion duration and pinching-degrading behavior on seismic response of SDOF systems. Soil Dyn Earthq Eng 114:333-347

Montejo LA, Kowalsky MJ (2007) CUMBIA—set of codes for the analysis of reinforced concrete members. CFL technical rep. no. IS-07, 1

Montejo LA, Kowalsky MJ (2008) Estimation of frequency-dependent strong motion duration via wavelets and its influence on nonlinear seismic response. Comput Aided Civ Infrastruct Eng 23(4):253-264

Montejo LA, Suarez LE (2013) An improved CWT-based algorithm for the generation of spectrum-compatible records. Int J Adv Struct Eng 5(1):26

Montejo LA, Vidot-Vega AL (2017) An empirical relationship between fourier and response spectra using spectrum-compatible times series. Earthq Spectra 33(1):179-199

Perez-Rivera E, Montejo LA (2017) Numerical evaluation of seismic soil pressures on rigid walls fixed to the bedrock. J Earthq Eng 21(1): 105-122

Schoettler MJ, Restrepo JI, Guerrini G, Duck DE, Carrea F (2015) A full-scale, single-column bridge bent tested by shake-table excitation. Pacific Earthquake Engineering Research Center, University of California, Berkeley

United States Nuclear Regulatory Commission (USNRC) (2007) Nuclear regulatory guide 1.208: a performance-based approach to define the site-specific earthquake ground motion, Washington, DC

Publisher's Note Springer Nature remains neutral with regard to jurisdictional claims in published maps and institutional affiliations. 